\title{
Molecular Insights of Carbon Nanodot Formation and Their Two-Photon Emission Properties
}

\author{
Nilanjon Naskar, ${ }^{a, b}$ Manfred Wagner, ${ }^{b}$ Hans Joachim Räder, ${ }^{b}$ Haoyuan Qi, ${ }^{c, d}$ Ute Kaiser, ${ }^{c}$ Tanja \\ Weil, $^{a, b}$ Sabyasachi Chakrabortty, ${ }^{a, b, e^{*}}$
}

Nilanjon Naskar, Tanja Weil, Sabyasachi Chakrabortty

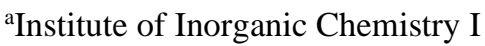

Ulm University

Albert-Einstein-Allee 11

89081 Ulm, Germany

Manfred Wagner, Hans Joachim Räder, Tanja Weil, Sabyasachi Chakrabortty
\[ { }^{\text {bept. of Synthesis of Macromolecules }} \]
Max Planck Institute for Polymer Research
Ackermannweg 10, 55128 Mainz, Germany

\author{
Haoyuan Qi, Ute Kaiser \\ 'Electron Microscopy Group of Materials Science \\ Ulm University \\ Albert-Einstein-Allee 11 \\ 89081 Ulm, Germany
}

\begin{abstract}
Haoyuan Qi
${ }^{\mathrm{d} C e n t e r ~ f o r ~ A d v a n c i n g ~ E l e c t r o n i c s ~ D r e s d e n ~(c f a e d) ~ \& ~ F a c u l t y ~ o f ~ C h e m i s t r y ~ a n d ~ F o o d ~ C h e m i s t r y ~}$ Dresden University of Technology

Mommsenstrasse 4, 01062 Dresden, Germany
\end{abstract}

Sabyasachi Chakrabortty

eDepartment of Chemistry

SRM University AP Andhra Pradesh

Andhra Pradesh 522502, India

*Corresponding author: sabyasachi.c@ srmap.edu.in 


\section{Abstract}

The structure formation of carbon nanodots (C-dots) prepared from three different organic precursors is discussed at the molecular level. During microwave synthesis, organic chromophores associated with C-dot structures are formed that exhibit distinct optical features. We have elucidated the molecular structure of these fluorophores and investigated their optical properties with and without the C-dots. The emergence of two-photon emission was observed and correlated with the hybridization state of the carbon atoms within the C-dot as well as the formation of the fluorophores. Varying contents of $\mathrm{sp}^{2}$ and $\mathrm{sp}^{3}$ hybridization in different C-dots also affects their one-photon and two-photon emission characteristics. Understanding the molecular structure of the carbon nanocore and the organic fluorophores formed in C-dots would enable rational design of C-dots with improved optical features, which would be of great relevance for their applications, for example, in bioimaging.

Keywords: Carbon nanodots, molecular fluorophores, two-photon emission, formation mechanism, hybridization, optical stability, fluorescence lifetime imaging microscopy 


\section{Introduction}

Carbon nanodots (C-dots) are sub-10nm fluorescent carbon nanoparticles synthesized from low cost organic precursors that showcase exciting properties such as biocompatibility ${ }^{1}$, photostability $^{2}$, easy surface functionalization ${ }^{3}$ or two-photon excited emissions $s^{4,5}$. These unique features have generated broad interest in sensing ${ }^{6}$, multimodal bio-imaging ${ }^{7}$, photo catalysis ${ }^{8}$, drug delivery ${ }^{9}$ and photonics ${ }^{10}$. C-dots are usually prepared by relatively simple synthetic procedures including top-down approaches such as laser ablation ${ }^{11}$, chemical ${ }^{12}$, and electrochemical oxidation ${ }^{13}$ as well as bottom-up methods like microwave irradiation ${ }^{14}$, ultrasonication ${ }^{15}$, and hydrothermal ${ }^{6} /$ solvothermal $^{16}$ approaches. However, the formation mechanism as well as the molecular structure of the C-dots, which can dictate their photoluminescence (PL) properties, is still barely understood. Several parameters such as the precursor molecules, the method of preparation, reaction time, and temperature could affect the optical properties of the as-synthesized C-dots. ${ }^{17-22}$ A molecular understanding on how the precursor's molecules affect the optical properties would be very useful to rationally design $\mathrm{C}$-dots with the desired optical features.

The PL characteristics of C-dots originate from the bandgap transitions of conjugated $\pi$ electron rich domains, recombination of surface-trapped charges, electron-hole pairs inside small $\mathrm{sp}^{2}$-carbon clusters or surface-trapped excitons. ${ }^{20,23-27}$ The occurrence of the emission of PL states was explained in various studies by quantum size effects, surface states and molecular states. For example, the inverse correlation between the HOMO-LUMO energy gap and the size of the graphitic layers has been proposed to explain the observed size dependent optical properties of different sized C-dots. ${ }^{28-31}$ In addition, several other studies suggested that the presence of surface emissive trap states, ${ }^{32-34}$ surface oxidation/reductions 
and modifications ${ }^{35-37}$ are responsible for the emissive behavior of C-dots. Their characteristic emission was suggested to originate from graphitic domains inside the carbonaceous core and extrinsically from surface states. ${ }^{38-40}$ It was proposed previously that $\mathrm{C}$-dots contain multiple chromophoric units connected to the carbonaceous core and that oxygenated surface defects form the emission traps. ${ }^{41}$ In alternative studies, it was shown that the photoluminescence could be dominated by organic fluorophores associated with the carbonaceous core or the surface. ${ }^{21}$ The yield of these organic fluorophores varies with synthesis temperature, and it was postulated that at high temperatures, these fluorophores are dehydrated, polymerized and then carbonized to produce highly photostable carbogenic cores of low quantum yield. ${ }^{21,22,42}$ Thus, elucidating the molecular structures of these fluorophores within the C-dots could lead to a better understanding of their observed optical properties.

Two-photon (TP) excited visible fluorescence, an optical phenomenon in which the emission wavelength can be shorter (of high energy) than the wavelength of the exciting photon, is attractive for bio-imaging applications as it can enhance tissue penetration and reduce background autofluorescence. ${ }^{43,44}$ Several studies have connected the occurrence of two-photon emission properties of C-dots to their mode of preparation..$^{30,45-47}$ These studies postulated multiphoton activation processes as a probable origin for the two-photon emission, where sequential absorption of two or more low energy photons can result in anti-Stokes-type photoluminescence ${ }^{48}$ However, a study by Shen and co-workers argued that the limitation of multiphoton excitation processes could be an insufficient explanation ${ }^{49}$ and Wen et al. suggested that TP emission could be an artefact originating from the excitation by the leaking light rays from the second diffraction inside the 
monochromator of the spectrophotometer, which could be removed by adding a suitable long-pass filter. ${ }^{50}$ Therefore, the origin of the two-photon emission of C-dots is still under debate.

Herein, we have studied the formation mechanism of organic fluorophores in C-dots synthesized by a straight-forward bottom-up approach by applying three different kinds of precursor molecules. We discuss the importance of the molecular precursors and how they could affect the observed optical properties of the as-synthesized C-dots. The emergence of two-photon emission properties of C-dots was attributed to the presence of $\pi$-electrons in the molecular precursors and the formation of fluorophores during C-dot synthesis. The $\mathrm{sp}^{2} / \mathrm{sp}^{3}$-hybridization of the carbonaceous core of the C-dots was investigated and improved two-photon emission properties were found for such C-dots consisting of relatively larger $\mathrm{sp}^{2}$-hybridized domains. The chemical structure of the formed fluorophores was resolved. We analyzed the photostability and biocompatibility of the C-dot with and without the fluorophores, and we could show that the presence of the carbonaceous core interacting with these fluorophores plays a crucial role in controlling their fluorescence stability. We envision that a molecular understanding of the chemical reactions occurring during $\mathrm{C}$-dot synthesis will provide new avenues for the rational design of C-dots with optimized optical features that would be of great interest for bioimaging.

\section{Results and Discussion}

\subsection{Synthesis and characterization of the C-dots}

Various C-dots were synthesized based on published protocols with citric acid (CA) as the main carbon source ${ }^{51,52}$ in combination with passivating agents such as 2aminoethylphosphonic acid (APA), polyvinylpyrrolidone (PVP), PEG-600 (PEG), PEGdiamine (PEGD), polyethylenimine (PE), ethylenediamine (EDA), and ophenylenediamine (PDA) (see structure in Figure 1). ${ }^{21,53-58}$ We employed microwave 
assisted synthesis to prepare three different types of C-dots in aqueous solution based on three different precursors, aromatic PDA and aliphatic EDA, both containing amino groups, as well as aliphatic PEG without amino groups. The corresponding C-dots solution were termed CAPDA, CAEDA and CAPEG, respectively. C-dot synthesis was performed for $20 \mathrm{~min}$ at $150^{\circ} \mathrm{C}(8 \mathrm{bar}, 70 \mathrm{~W})$ in the microwave synthesizer. Then, the $\mathrm{C}$-dots were purified through a $0.2 \mu \mathrm{m}$ pore-sized cellulose membrane-based syringe filter to remove any larger aggregates present in solution. In addition, dialysis was employed to purify the C-dots from unreacted precursors and other byproducts. Polyacrylamide gel electrophoresis (Nu-PAGE) showed that CAEDA-p C-dots have larger dimensions than CAPDA-p C-dots as they diffused slower through the electrophoresis distance as shown in Figure S1. The average sizes of the C-dots were obtained using transmission electron microscopy (TEM) and narrowly dispersed particles of $2.3 \pm 0.6 \mathrm{~nm}$ (CAPDA-p), $4.3 \pm 1.4 \mathrm{~nm}$ (CAEDA-p) and $4.5 \pm 2.1 \mathrm{~nm}$ (CAPEG-p) were found (Figure 1d-i) that could be dispersed in aqueous solution without the formation of larger aggregates.

C-dots were dispersed in water and CAPDA (greenish yellow) and CAEDA (reddishyellow color) revealed characteristic colors, whereas CAPEG appeared colorless. We supposed that these optical properties of the CAPDA and CAEDA nanoparticles could be related to the formation of carbonaceous cores and with the associated fluorophores (Figure 1a, 1b) and that in case of CAPEG, no associated fluorophores were formed (Figure 1c). In the following, we have first investigated the C-dot cores CAPDA-p, CAEDA-p and CAPEG-p and then elucidated the molecular structures of the formed fluorophores to correlate the observed optical properties to structural features of the fluorophore-associated C-dots. 
(a)<smiles>Nc1ccccc1N</smiles>

(b)<smiles>[12CH3]CNCCN</smiles>

(c)<smiles>O=C(O)CC(O)(CC(=O)O)C(=O)O</smiles>

CA<smiles>CC(C)OCCC(C)(C)O</smiles>

PEG

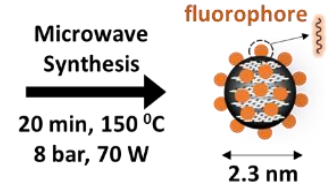

CAPDA Carbonaceous Core (CAPDA-p)

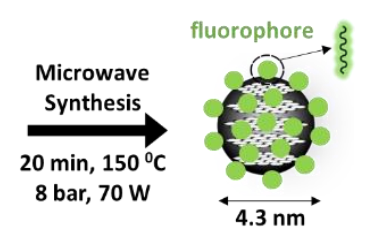

CAEDA Carbonaceous Core (CAEDA-p)

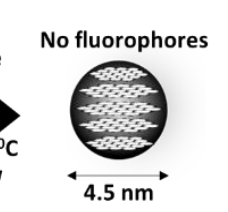

CAPEG Carbonaceous Core (CAPEG-p) (d)

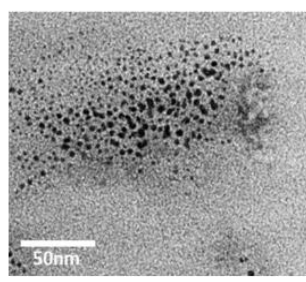

(f)

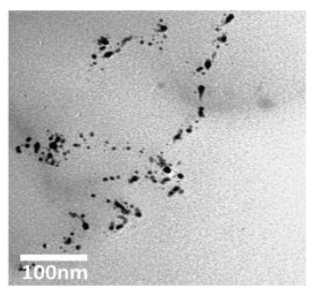

(h)

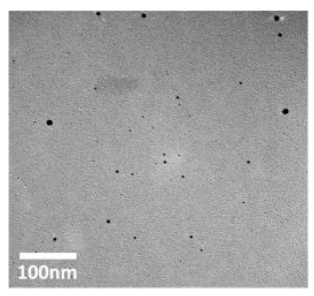

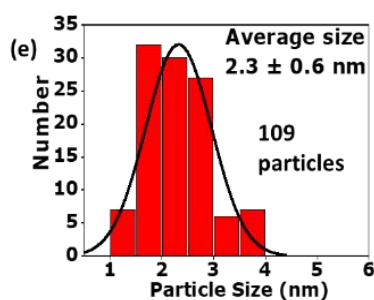

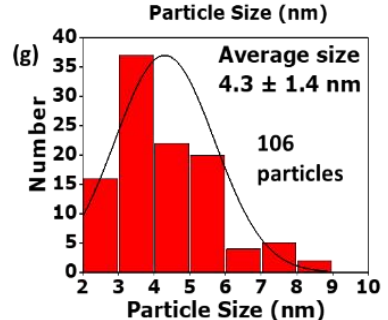

(i) $100 \quad$ Particle Size $(\mathrm{nm})$

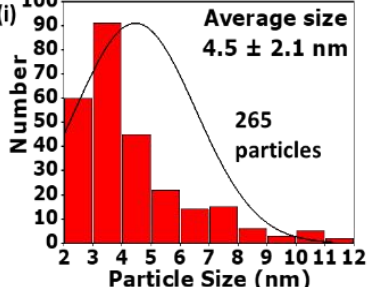

Figure 1. (a-c) Schematic representation of C-dot synthesis, where citric acid (CA) was used in combination with three different precursor molecules (PDA, EDA and PEG) to obtain C-dots in solution. Under microwave irradiation, a carbonaceous core and molecular fluorophores were obtained simultaneously for CAPDA (CAPDA-p) and CAEDA (CAEDA-p) precursors. In case of CAPEG (CAPEG-p), no fluorophores were formed. Bright-field TEM images and the corresponding size distributions are depicted in (d-e) for CAPDA, (f-g) for CAEDA, and (h-i) for CAPEG. These obtained C-dots were narrowly dispersed with average sizes of $2.3 \mathrm{~nm}$ (CAPDA-p), $4.3 \mathrm{~nm}$ (CAEDA-p) and 4.5 nm (CAPEG-p), respectively.

\subsection{Characterization of the composition, interlayer spacing and energy bandgap of the}

\section{C-dots cores}

X-ray photoelectron spectroscopy (XPS) characterization was performed to investigate the surface composition of the obtained C-dots. The deconvolution of high resolution $\mathrm{C} 1 \mathrm{~s}$ spectra revealed the presence of three peaks around $284.5 \mathrm{eV}, 285.8 \mathrm{eV}$ and $288.5 \mathrm{eV}$ for the C-dots CAPDA-p, CAEDA-p, CAPEG-p. We attributed these peaks to $\mathrm{C}=\mathrm{C}\left(\mathrm{sp}^{2}\right), \mathrm{C}-\mathrm{C}$ $\left(\mathrm{sp}^{3}\right), \mathrm{C}-\mathrm{H}, \mathrm{C}=\mathrm{O}$ or $\mathrm{COOH}$ surface functionalities of the C-dots. ${ }^{59}$ Quantitative analysis revealed a $\mathrm{sp}^{2}, \mathrm{sp}^{3}$-carbon ratio for C-dots CAPDA-p, CAEDA-p and CAPEG-p of 1.28, 0.47 and 0.90, respectively (Figure 2a-c). A relatively higher content of $\mathrm{sp}^{2}$-hybridized carbon of the CAPDA-p C-dot surface could originate from the aromatic PDA precursor. 
X-ray diffraction (XRD) characterization was performed to investigate the crystallinity of the C-dots. A broad diffraction pattern indicating amorphous-like, rather distorted structures ${ }^{59}$ consisting of a mixture of $\mathrm{sp}^{2}$ - and $\mathrm{sp}^{3}$ - hybridized carbon atoms was observed. CAPDA and CAEDA showed a broad characteristic peak angle at $19.50^{\circ}$ and $17.64^{\circ}$, respectively, indicating the presence of a heterogeneous environment of the carbon atoms within the crystal structure (Figure S2). In comparison, graphite, comprising of pure $\mathrm{sp}^{2}$ hybridized domains, has a characteristic peak angle of $26.60^{\circ} .{ }^{60}$

Aberration-corrected high resolution transmission electron microscopy (AC-HRTEM) (Figure 2d-f) and selected area electron diffraction (SAED) was carried out to characterize the interplanar spacing inside the different C-dots. CAPDA-p revealed a characteristic inplane lattice spacing of $0.23 \mathrm{~nm}$ close to the (100) diffraction plane of graphite ${ }^{61}$ and stacked planar structures of smaller dimensions were found resembling honeycomb graphitic structures. ${ }^{26,27,62}$ The sharp diffraction spots demonstrate the high crystallinity of the C-dots. The largest lattice plane spacing's obtained from SAED patterns (Figure 2g-i) were $0.344 \mathrm{~nm}$ (CAPDA-p), $0.368 \mathrm{~nm}$ (CAEDA-p), and $0.475 \mathrm{~nm}$ (CAPEG-p), which correspond to the interlayer distance within the C-dots. Interestingly, the interlayer distance in graphite is $0.335 \mathrm{~nm},{ }^{60}$ which is in a similar range as the spacing found in the CAPDAderived C-dots. The high $\mathrm{sp}^{2}$-hybridization content from the aromatic PDA precursor in CAPDA could influence the interlayer spacing that possibly resulted in much smaller interplanar distances in C-dot CAPDA-p. The superior crystallinity of the C-dots was further confirmed by AC-HRTEM imaging, from which the lattice planes are clearly resolved. 

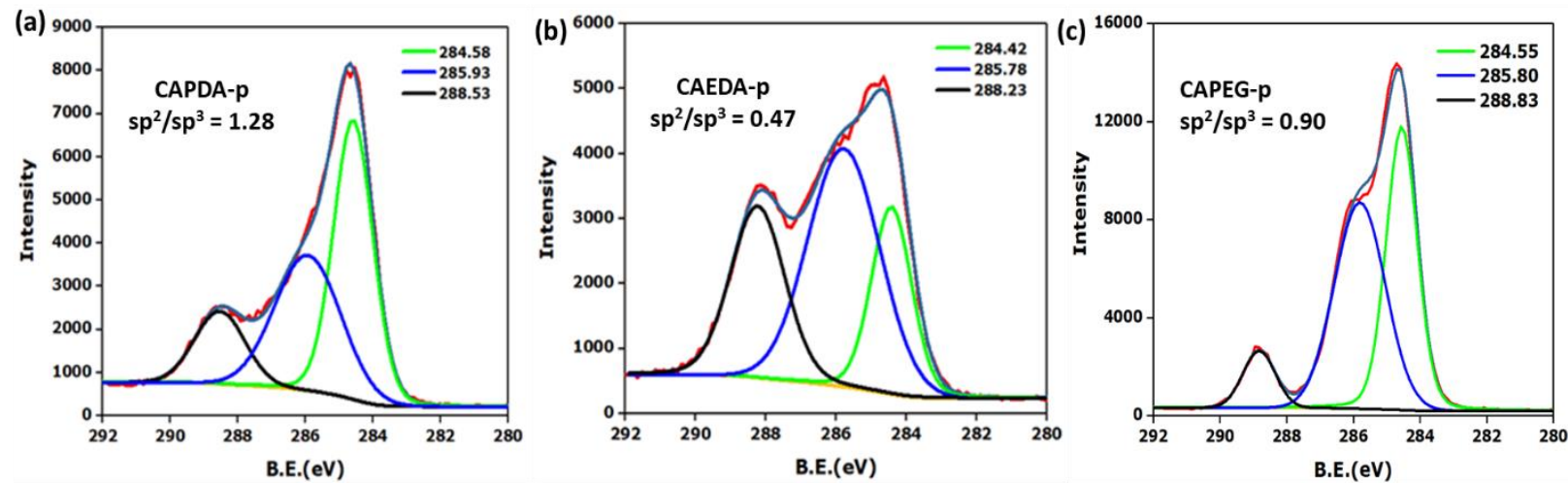

(d)

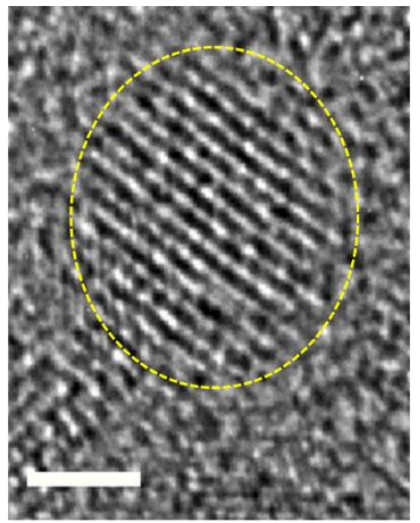

(e)

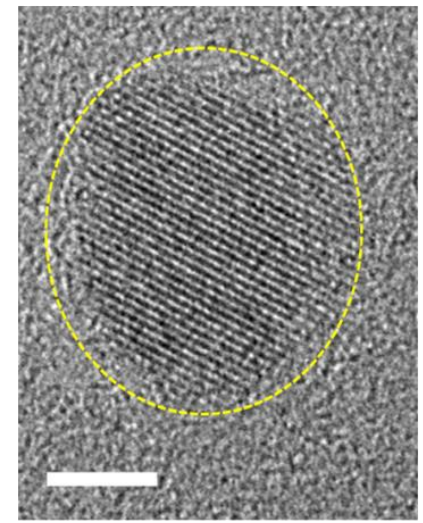

(f)

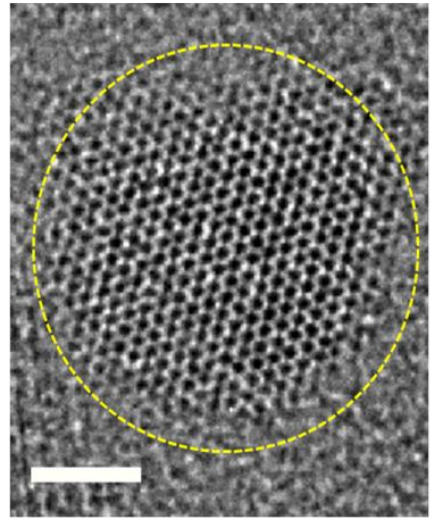

(g)

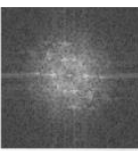

(h)

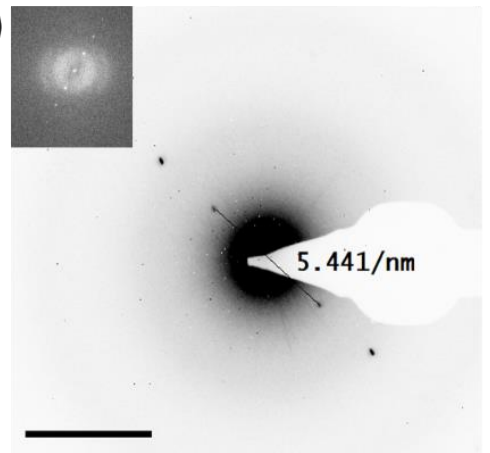

(i)

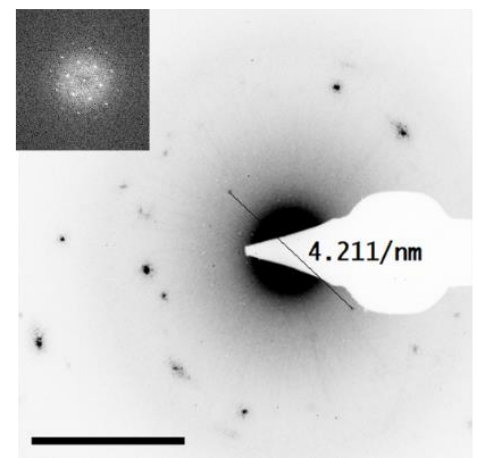

Figure 2. (a-c) C1s XP spectra of the C-dot cores CAPDA-p, CAEDA-p and CAPEG-p. (d-f) The HRTEM images of all three $\mathrm{C}$-dots cores showed characteristic lattice planes with $0.23 \mathrm{~nm}$ d-spacing in CAPDA-p. The scale bar (d) $2 \mathrm{~nm}$, (e) $4 \mathrm{~nm}$ and (f) $2 \mathrm{~nm}$. (g-i) SAED patterns of the C-dots cores clearly showed the interplanar spacing as $(\mathrm{g}) 0.344 \mathrm{~nm}$ for CAPDA-p, (h) $0.368 \mathrm{~nm}$ for CAEDA-p and (i) $0.475 \mathrm{~nm}$ for CAPEG-p. The scale bar (g) $5 \mathrm{~nm}^{-1}$, (h) $5 \mathrm{~nm}^{-1}$ and (i) $4 \mathrm{~nm}^{-1}$.

To assess the $\mathrm{sp}^{2}, \mathrm{sp}^{3}$-hybridization content of the C-dot core, electron energy loss spectroscopy (EELS) was performed. The EELS spectra from the carbon K-edge of carbonaceous cores were deconvoluted using the "three-Gaussian" fitting method, ${ }^{63}$ where 
a linear combination of three Gaussian functions were fitted in the $\pi^{*}$ and $\sigma^{*}$ energy regions. The first two functions were centered at $285.0 \mathrm{eV}$ and $287.8 \mathrm{eV}$, which denotes the transition to the $\pi^{*}$-state ( $\mathrm{sp}^{2}$-bonding) and the third function was set at $292.2 \mathrm{eV}$ that represented the transition to the $\sigma^{*}$-state ( $\mathrm{sp}^{3}$-bonding). ${ }^{63-65}$ Quantitative analysis revealed $\mathrm{sp}^{2}, \mathrm{sp}^{3}$-bonding ratios for C-dots CAPDA-p, CAEDA-p and CAPEG-p as 0.61, 0.45 and 0.13, respectively (Figure S4, Table S1). This confirmed the presence of relatively larger $\mathrm{sp}^{2}$-domains in CAPDA-p C-dots. Furthermore, Raman measurements were also carried out to investigate the carbon structure. The Raman spectra showed the presence of two clear signature peaks around $1358 \mathrm{~cm}^{-1}$ (D-band) and $1586 \mathrm{~cm}^{-1}$ (G-band) in the carbonaceous cores. The D-band corresponds to structural defects in graphitic $\mathrm{sp}^{3}$-hybridized carbon and the G-band is represented by disordered $\mathrm{sp}^{2}$-hybridized carbon clusters. The Raman spectra were deconvoluted and their corresponding areas were used to estimate the $\mathrm{sp}^{2}$ - to $\mathrm{sp}^{3}$ carbon ratio $\left(\mathrm{I}_{\mathrm{G}} / \mathrm{I}_{\mathrm{D}}\right.$ ratio) (Figure S5). A reduction of the ratio from 1.4 for the CAPDA-p core to 0.8 for the CAEDA-p core indicated comparatively higher $\mathrm{sp}^{2}$-content inside the CAPDA-p C-dots. Next, we investigated the formation of molecular fluorophores.

\subsection{Characterizations of the molecular fluorophores associated with C-dots}

The citric acid and the amine precursor react under microwave conditions and polymerization, dehydration and continuous aromatization could occur that could lead to the formation of the Cdots as well as fluorophore molecules. In order to assess, whether C-dots and associated fluorophores were formed, we applied repeated dialysis purification to separate the carbonaceous C-dot cores from the free molecular fluorophores in solution. We envision that the C-dots are associated with fluorophores similar structures that are either bound covalently or strongly physisorbed at their surface or mechanically trapped inside the C-dot structure. The CAPDA and 
CAEDA C-dots suspension turned colorless (as depicted Figure S6a digital image, schematic illustration in Figure S6b) after purification by dialysis and HPLC (Figure S7), and the fluorescent solutions containing the fluorophores were isolated. In contrast, dispersed CAPEG as well as its surrounding solution appeared colorless indicating that no fluorophores were formed. Purified fractions showed the presence of two chromophore molecules corresponding to fluorophore $\mathbf{1}$ that was formed in about $25 \%$ yield (structure $1,264.07 \mathrm{~g} / \mathrm{mol}, \mathrm{C}_{12} \mathrm{H}_{12} \mathrm{~N}_{2} \mathrm{O}_{5}$ ) and fluorophore 2 that was formed in about $63 \%$ yield (structure $2,246.06 \mathrm{~g} / \mathrm{mol}, \mathrm{C}_{12} \mathrm{H}_{10} \mathrm{~N}_{2} \mathrm{O}_{4}$ ) as depicted in Figure 3. The yield was estimated from NMR but inside the measured solution obtained from the fractions F1-F3 (Figure S7). Also, some impurities could not be removed and were detected in HPLC and in the NMR spectrum. The structures of the isolated fluorophores from CAPDA (1 and $\mathbf{2})$ and CAEDA $3\left(216.07 \mathrm{~g} / \mathrm{mol}, \mathrm{C}_{8} \mathrm{H}_{12} \mathrm{~N}_{2} \mathrm{O}_{5}\right)$ were analyzed by ${ }^{1} \mathrm{H}-\mathrm{NMR}$ as depicted in Figure 3a, 3b, S8, S15, ${ }^{13} \mathrm{C}-\mathrm{NMR}$ (Figure S9, S16), ${ }^{1} \mathrm{H}^{13} \mathrm{C}$ HSQC (Figure S10, S17), ${ }^{1} \mathrm{H}^{13} \mathrm{C}$ HMBC (Figure S11, S18), COSY (Figure S12, S19) and DOSY (Figure S13, S20). The shorter relaxation time due to the interaction of the connected quadrupole nuclei ${ }^{14} \mathrm{~N}$ to the neighbored dipole carbon atoms can be a plausible reason for broadening the ${ }^{13} \mathrm{C}-\mathrm{NMR}$ signal ${ }^{66}$ and resulting in the signal disappearance of carbon atom C8 in CAPDA fluorophore and C5 in CAEDA fluorophore (Figure S9, S14, S16). The signals of two coupled AB systems were identified and assigned $\left(\mathrm{CH}_{2}\right.$ groups $\mathrm{C} 11, \mathrm{C} 13$ in structure $\mathbf{1}, \mathrm{CH}_{2}$ groups $\mathrm{C} 30, \mathrm{C} 33$ in structure $\mathbf{2}$ of the CAPDA fluorophore and $\mathrm{CH}_{2}$ groups $\mathrm{C} 1, \mathrm{C} 2$ and $\mathrm{C} 7, \mathrm{C} 10$ in structure $\mathbf{3}$ of the CAEDA fluorophore) (Figure 3a, 3b, S8, S15). The ${ }^{1} \mathrm{H}-\mathrm{NMR}$ signals of coupled hydrogen systems (H20, H21 and H22, H23) in CAEDA fluorophore were identified from ${ }^{1} \mathrm{H}-{ }^{13} \mathrm{C}$ HSQC and ${ }^{1} \mathrm{H}-{ }^{13} \mathrm{C}$ HMBC spectra (Figure S17, S18). The proposed molecules and their elemental compositions were further confirmed by accurate mass and MS/MS analysis (Figure 3c, 3d, S21 and Table S2). The highly symmetric structure 2 
$\left(\mathrm{C}_{12} \mathrm{H}_{10} \mathrm{~N}_{2} \mathrm{O}_{4}\right)$ is a condensation product of structure $\mathbf{1}\left(\mathrm{C}_{12} \mathrm{H}_{12} \mathrm{~N}_{2} \mathrm{O}_{5}\right)$. But the signals of structure 2 were not detectable in the mixture possibly because of ionization suppression effects. However, the fragmentation pattern of the CAPDA fluorophore molecular ion $(\mathrm{m} / \mathrm{z}=265.08)$ showed the presence of signals at $\mathrm{m} / \mathrm{z} 247.06$ and 229.05 suggesting that such cyclic molecules detected by NMR are very probable intermediates from one of the fluorophores in the mixture (Figure S22). In general, the fragmentation pattern of the fluorophores show multiple mass differences of $\mathrm{m} / \mathrm{z}$ 18.01 for $\mathrm{H}_{2} \mathrm{O}$ and 43.99 for $\mathrm{CO}_{2}$ indicating that the main decomposition pathway is dehydration and decarboxylation and thus confirming the presence of $-\mathrm{OH}$ and $-\mathrm{COOH}$ functional groups in the precursor molecules. Furthermore, similar ions with a molecular mass of $217.08\left(\mathrm{MH}^{+}\right)$were found for fluorophores synthesized from citric acid and passivating agents ethylenediamine and 1,10-diaminodecane (DAD) under identical reaction conditions (Figure S23). The MS/MS spectra together with the elemental compositions from accurate mass measurements and structural confirmation from NMR unambiguously prove the proposed structures. Formation of stable, low ring strain five and six-membered structures during condensation and aromatization processes can be a probable reason for the formation of similar chemical structures from a longer alkyl chain containing precursor DAD molecule. Probable formation mechanism of the proposed fluorophores are illustrated in Figure 3e, 3f. 

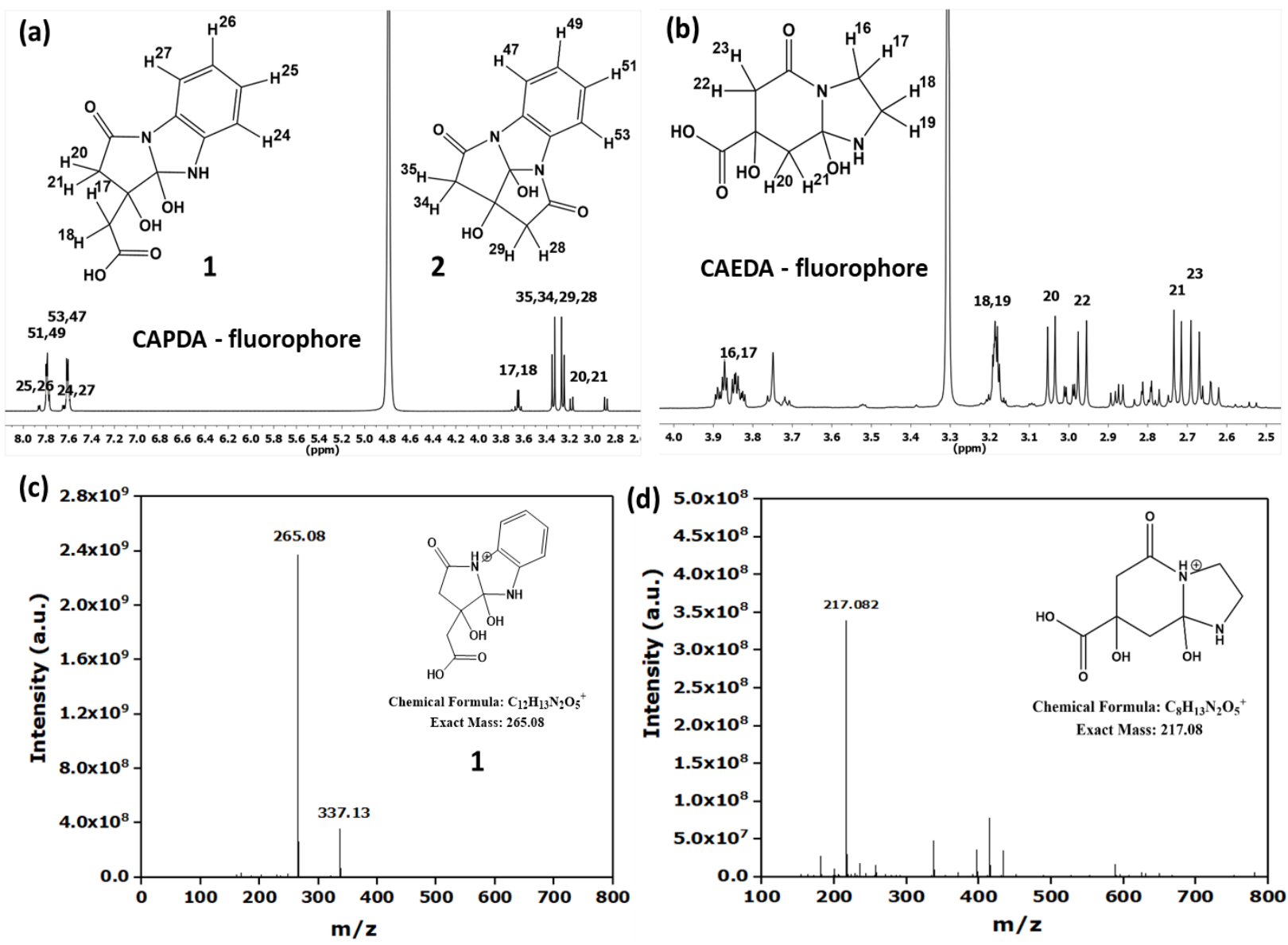

(e)

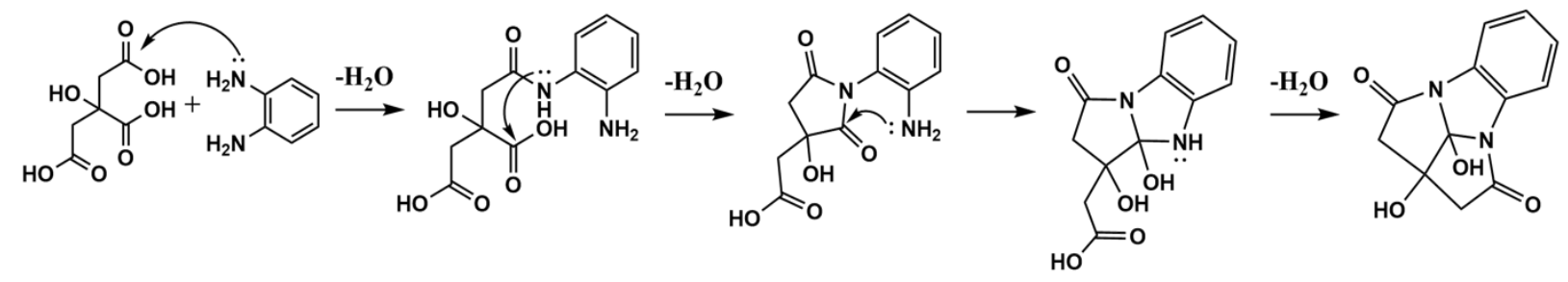

(f)

1

2

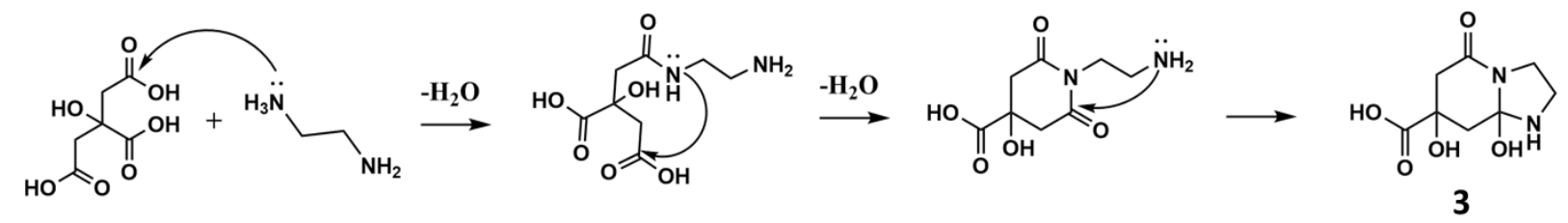

Figure 3. ${ }^{1} \mathrm{H}-\mathrm{NMR}$ characterizations of molecular fluorophore for the C-dots: (a) CAPDA, two molecules were detected in the measured solution: 1 (264.07 g/mol, $\left.\mathrm{C}_{12} \mathrm{H}_{12} \mathrm{~N}_{2} \mathrm{O}_{5}\right)$ and 2 (246.06 $\mathrm{g} / \mathrm{mol}$, $\left.\mathrm{C}_{12} \mathrm{H}_{10} \mathrm{~N}_{2} \mathrm{O}_{4}\right)$ in $25 \%$ and $63 \%$ yield, respectively; (b) CAEDA fluorophore 3 (216.07 $\mathrm{g} / \mathrm{mol}$, $\mathrm{C}_{8} \mathrm{H}_{12} \mathrm{~N}_{2} \mathrm{O}_{5}$ ). ESI-MS spectra showing the mass signals of the fluorophores associated to the C-dots: (c) CAPDA $\left(\mathrm{MH}^{+} 265.08\right)$ and (d) CAEDA $\left(\mathrm{MH}^{+}\right.$217.08). Schematic diagram of the proposed formation 
mechanism for the synthesis of the molecular fluorophores associated with the C-dots CAPDA (e) and CAEDA (f).

\subsection{Optical properties and two-photon emission of the dispersed C-dots and the associated chromophores}

All C-dots elicit a characteristic first absorbance peak in the ultraviolet region, i.e., between 350$400 \mathrm{~nm}$ (Figure 4a-c), and there was no appreciable absorption beyond $400 \mathrm{~nm}$. C-dots obtained from CAPDA and CAEDA showed excitation independent emission spectra (250-400 nm excitation range), whereas the emission of CAPEG was excitation dependent $(300-400 \mathrm{~nm}$ excitation range). After excitation at $\sim 350 \mathrm{~nm}$, fluorescent quantum yields (QY) of $28 \%$ (CAPDA), 72\% (CAEDA) and 13\% (CAPEG) were determined. A larger core size in CAEDA-p might be responsible for higher relative fluorescent QY compared to CAPDA. ${ }^{20}$ The presence of $\mathrm{N}$-atoms in the precursors could lead to higher QY in CAPDA and CAEDA compared to CAPEG. ${ }^{21,67}$ We also performed photostability experiments on the C-dot cores, and the isolated fluorophores are depicted in Figure 4d. The C-dot cores or the isolated fluorophore molecules were embedded in an agarose gel and continuously irradiated with one-photon laser excitation of wavelength $405 \mathrm{~nm}$ for about $6 \mathrm{~min}$. The carbonaceous core CAPDA-p was significantly more photostable compared to the free molecular fluorophores $\mathbf{1}$ and $\mathbf{2}$ given in Figure 3.

Next, the CAPDA and CAEDA C-dots were subjected to an $810 \mathrm{~nm}$ laser excitation source to determine their two-photon (TP) absorption properties. Both CAPDA and CAEDA C-dots exhibited maximum two-photon emission at $810 \mathrm{~nm}$ excitation wavelength. Thus, we employed the same mass concentration i.e., $1 \mathrm{mg} / \mathrm{mL}$ for further comparison. Although CAEDA showed higher one-photon QY, we observed higher fluorescence intensity in the visible region for CAPDA derived C-dots after $810 \mathrm{~nm}$ excitation (Figure 5a-d). 

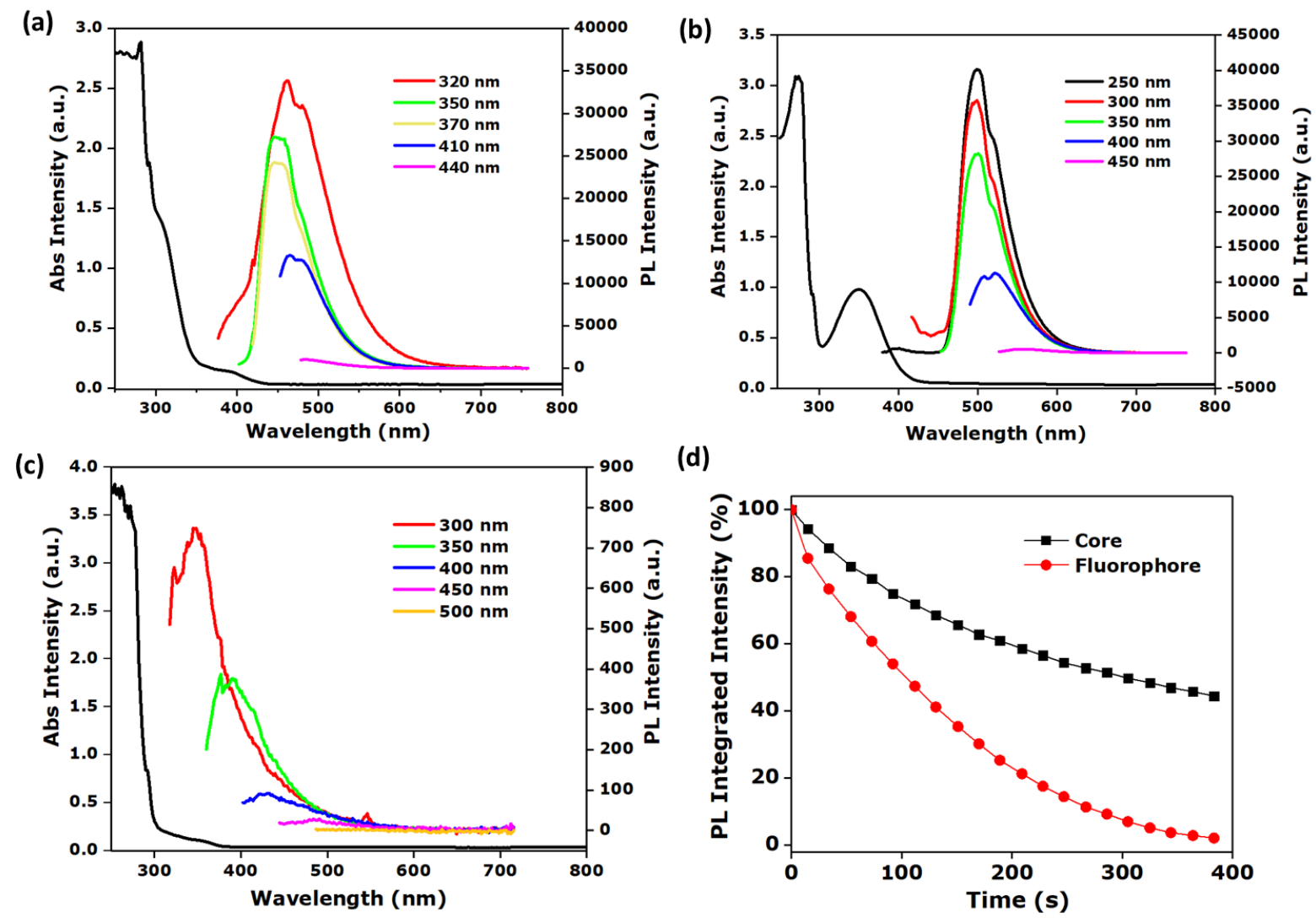

(d)

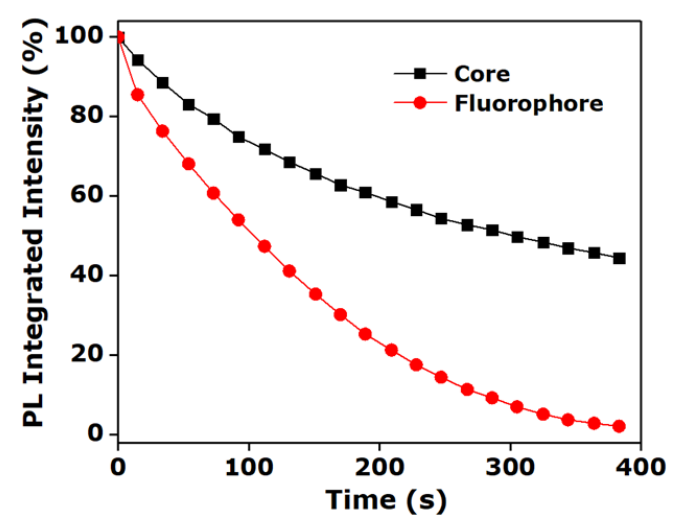

Figure 4. (a-c) The photoluminescence spectra at different excitation sources are shown for various $\mathrm{C}$-dots solution i.e., CAPDA, CAEDA, and CAPEG, respectively. Excitation independent PL emissions were observed for CAPDA and CAEDA C-dots; whereas excitation dependent emission was observed in CAPEG derived C-dots. (d) Photostability evaluations of representative carbonaceous core CAPDA-p and the associated CAPDA derived fluorophore using $405 \mathrm{~nm}$ laser and $5 \%$ laser power.

In addition, CAPDA nanodots revealed an enhanced two-photon absorption cross section (TPACS) of $17.8 \mathrm{GM}$, whereas CAEDA nanodots have a considerably lower TPACS of 3.1 GM (Figure 5e). Materials displaying higher TPACS are attractive for various bioapplications as they offer deeper tissue penetration. ${ }^{44}$ Interestingly, if an excitation wavelength of $400 \mathrm{~nm}$ was applied, the one-photon emission intensity of an optically matched (i.e., of the same optical density) CAPDA C-dot solution was higher than that of CAEDA nanoparticles. In contrast, CAEDA C-dots emitted relatively higher PL at other excitations namely $300 \mathrm{~nm}, 350 \mathrm{~nm}$, and $450 \mathrm{~nm}$ (Figure 5f). We believe that the higher 
one-photon emission of the CAPDA C-dot after $400 \mathrm{~nm}$ excitation corroborates with its larger two-photon absorption and emission properties at near $800 \mathrm{~nm}$. We predict that the two-photon absorption and emission properties of CAPDA C-dots could be due to the higher $\pi$-electron content. In addition, we have performed the same two-photon (Figure S25) excitation and compared the emission intensities from both carbonaceous cores CAPDA-p and CAEDA-p and their separated fluorophores $\mathbf{1}$ and $\mathbf{2}$. However, we did not find any significant change in their optical features implying a close association between the carbonaceous cores and the respective fluorophores.
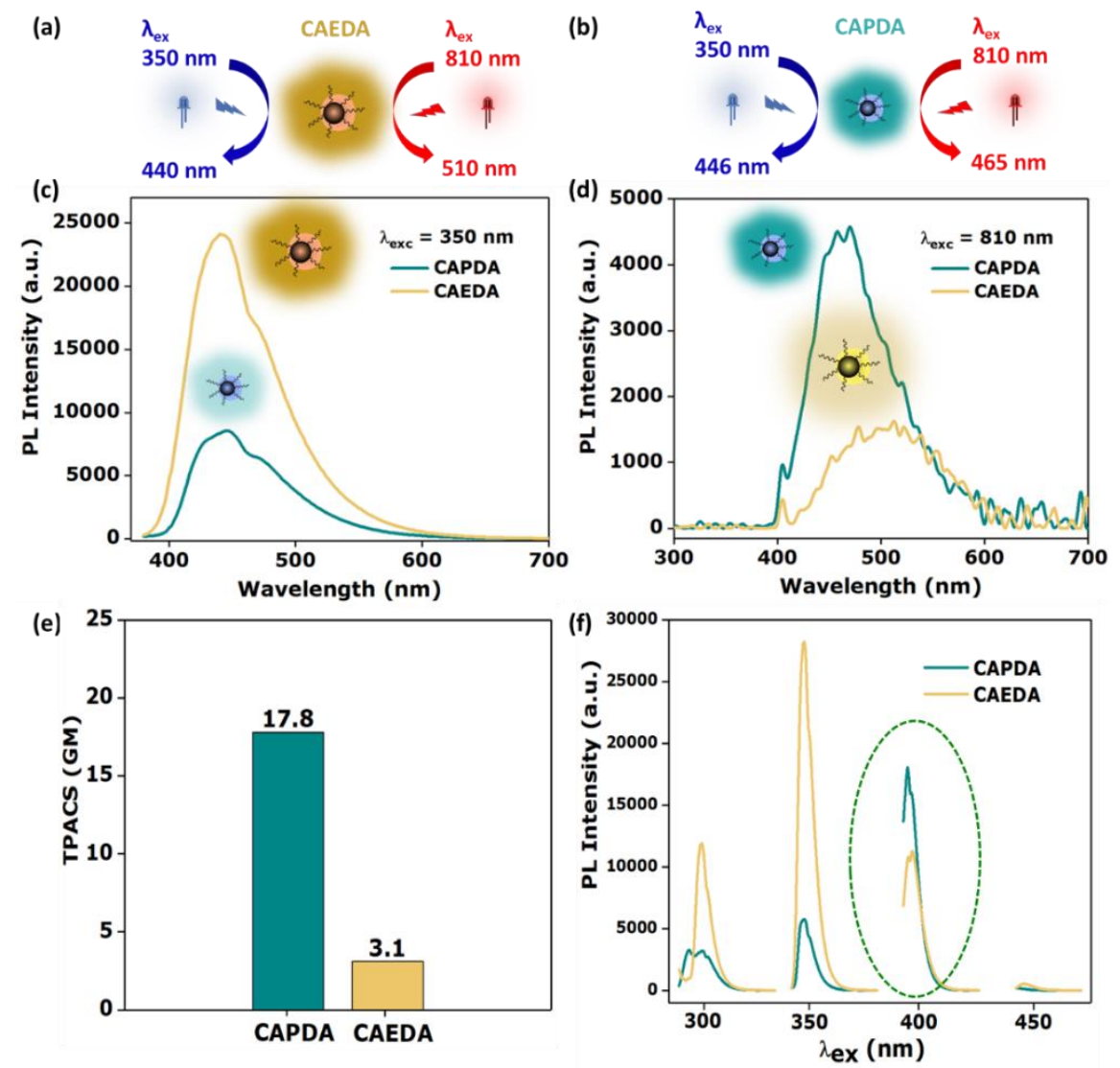

Figure 5. $(a, b)$ Scheme of two-photon and one-photon emissions of C-dots CAPDA and CAEDA that were excited at two different wavelengths, namely $350 \mathrm{~nm}$ and $810 \mathrm{~nm}$. (c,d) Corresponding PL characteristic peaks of both C-dots $(1 \mathrm{mg} / \mathrm{mL}$ each). After excitation at $350 \mathrm{~nm}$, CAEDA revealed higher PL than CAPDA, whereas after excitation at $810 \mathrm{~nm}$ using an FL 6500 Pulse Fluorescence Spectrophotometer at $80 \mathrm{~kW}$ power, $400 \mathrm{~V}$, CAPDA revealed higher PL instead. (e) Two-photon absorption cross section (TPACS) of C-dots CAPDA and CAEDA measured in water at an excitation wavelength of $810 \mathrm{~nm}$ using 
Rhodamine B as reference. (f) PL behaviour of as-prepared C-dots CAPDA and CAEDA under different one-photon excitation $(300 \mathrm{~nm}, 350 \mathrm{~nm}, 400 \mathrm{~nm}$, and $450 \mathrm{~nm}$ ) and same mass concentration $1 \mathrm{mg} / \mathrm{mL}$. Interestingly, the PL emission of C-dot CAPDA was significantly higher compared to C-dot CAEDA at $400 \mathrm{~nm}$ excitation (green dashed circle).

\subsection{Correlation of the structure and the optical properties of the C-dots and their associated chromophores}

The energy gap of the carbonaceous cores of CAPDA-p and CAEDA-p were measured as 1.91 and $1.56 \mathrm{eV}$, respectively, using cyclic voltammetry (CV). The observed band gap decrease in CAEDA-p was further substantiated by optical band gap calculations determined from the UV-Vis absorption spectra, which gave a band gap of 2.59 and $1.94 \mathrm{eV}$ for CAPDA-p and CAEDA-p, respectively (Table 1, Figure S26, S28). Additionally, the energy band gaps of the CAPDA- and CAEDA-derived fluorophores (1, 2 and $\mathbf{3}$, respectively) were simulated ${ }^{21}$ using TD-SCF DFT calculations implemented in the Gaussian package (Gaussian 09W, version 9.5), ${ }^{68,69}$ applying the B3LYP method, the DGTZVP basis set and the CPCM solvation model of water. Interestingly, the energy band gap showed an opposite trend for separated associated fluorophores. The HOMO-LUMO energy gaps were calculated to be $5.04 \mathrm{eV}, 4.17 \mathrm{eV}$ (both CAPDA-derived fluorophores $\mathbf{1}$, 2) and $5.40 \mathrm{eV}$ (CAEDA-derived fluorophore 3) (Table 1, Figure S29). The observed energy gap trend in the molecular fluorophores could be attributed to the presence of $\pi$ electrons in the benzene ring in the CAPDA fluorophores with extended electron delocalization resulting in a lower band gap. Table 1 summarizes the trend in the $\mathrm{sp}^{2}$ - and $\mathrm{sp}^{3}$-hybridization ratios and the HOMO-LUMO energy gap (eV) across various C-dots that were characterized by different techniques. We believe, the presence of increased $\pi$ electrons in CAPDA C-dots may have a strong influence on their two-photon emission features. 


\begin{tabular}{|c|c|c|c|c|c|c|}
\hline \multirow{2}{*}{$\begin{array}{c}\text { Characteristic } \\
\text { properties }\end{array}$} & Method & \multicolumn{3}{|c|}{ Carbonaceous Cores } & \multicolumn{2}{c|}{ Fluorophore } \\
\cline { 3 - 7 } & & CAPDA-p & CAEDA-p & CAPEG-p & CAPDA & CAEDA \\
\hline \multirow{2}{*}{$\begin{array}{c}\text { Ratio between } \\
\text { sp }^{2} \text { and sp } \\
\text { hybridization }\end{array}$} & XPS binding energy & 1.28 & 0.47 & 0.90 & 1.21 & 0.66 \\
\cline { 2 - 7 } & Raman peak & 1.4 & 0.8 & - & - & - \\
\hline \multirow{2}{*}{$\begin{array}{c}\text { HOMO-LUMO } \\
\text { energy gap (eV) }\end{array}$} & EELS & 0.61 & 0.45 & 0.13 & - & - \\
\cline { 2 - 7 } & Cyclic Voltammetry & 1.91 & 1.56 & 1.67 & - & - \\
\cline { 2 - 7 } & Gaussian Calculations & - & - & - & $5.04,4.17$ & 5.40 \\
\hline
\end{tabular}

Table 1. Characterization of the carbonaceous cores CAPDA-p, CAEDA-p and CAPEG-p and their associated molecular fluorophores 1, 2 and 3. The $\mathrm{sp}^{2}$ - and $\mathrm{sp}^{3}$-hybridized carbon content of the C-dots were estimated from XPS, Raman and EELS measurements. The energy band gaps of C-dots were evaluated from UV-Vis, cyclic voltammetry and Gaussian calculations.

Next, we have investigated the nature of the association between the fluorophores and the carbon nanodot by applying XPS, Fourier-transform infrared spectroscopy (FTIR), electrospray ionization mass spectrometry (ESI-MS) and their optical characterizations. We found that the $\mathrm{sp}^{2}-, \mathrm{sp}^{3}$-carbon ratio on the surface of the C-dot core CAPDA-p (1.28) appears in a similar range as the carbon ratio of its associated molecular fluorophore (1.21), determined by XPS characterizations (Figure 2a-c, S30, Table S3-S5). Also, the carbon ratio of the surface of the core CAEDA-p and the corresponding fluorophore 3 were similar with 0.47 and 0.66 , respectively. These data could indicate remaining fluorophores associated with the $\mathrm{C}$-dot core, which were challenging to separate by dialysis. FTIR studies of CAPDA-p C-dot core and the free fluorophores $\mathbf{1}$ and $\mathbf{2}$ were performed and many identical IR bands (Figure S31a, S31b) such as the broad O-H stretching frequency at $\sim 3050 \mathrm{~cm}^{-1}$, the $\mathrm{C}=\mathrm{O}$ stretching of carboxylic acids at $1713 \mathrm{~cm}^{-1}$ and prominent aromatic $-\mathrm{C}=\mathrm{C}$ stretching vibrations at $1578 \mathrm{~cm}^{-1}$ and $1392 \mathrm{~cm}^{-1}$ were found. ESI-MS data depicted in Figure S32 indicated similar molecular ions $\left(\mathrm{MH}^{+}\right)$of the CAPDA derived fluorophores 
(265.08) with the C-dot core CAPDA-p (265.13). We believe that the observed fluorophores in the ESI-MS of the purified carbonaceous cores were generated during sample preparation. The slightly acidic conditions of the ESI solvent could cause a physical or chemical detachment of fluorophores from the core surface. Additionally, we uncovered that the C-dot CAPDA-p core as well as the separated fluorophores showed similar characteristic one-photon absorption and emission peaks at $450 \mathrm{~nm}$ under $400 \mathrm{~nm}$ excitation (Figure S34 in CAPDA C-dots) as well as similar characteristic two-photon emission peaks after $810 \mathrm{~nm}$ excitation (Figure S25). Therefore, even after several thorough washing steps and purification via dialysis, the presence of fluorophores in the carbonaceous cores could still be detected. Most likely, the fluorophores could be associated through covalent and non-covalent conjugation with the carbonaceous core. In this case, the carbonaceous core could stabilize the organic fluorophore so that they do not bleach easily, whereas the fluorophore could serve as two-photon emission center.

\subsection{Cytotoxicity of the carbon nanodots}

C-dots have been used as drug delivery vehicles ${ }^{70,71}$ as their surface could be functionalized easily though bioconjugation reactions, ${ }^{72,73}$ and they could be easily detected allowing their intracellular imaging and tracking. ${ }^{7}$ In particular, their application as two-photon

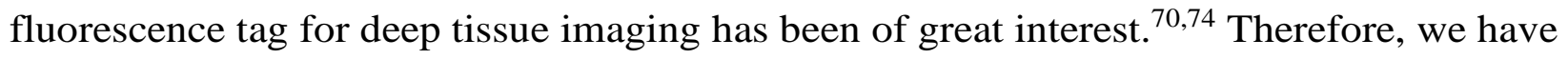
studied the C-dots in vitro and cell viability tests (Tox-8 assays) have been performed with various weight concentrations using HeLa cells as cell model. Both the purified carbonaceous core CAPDA-p and the C-dot solution reveal low cytotoxicity applying a HeLa cell line even at high concentrations $500 \mu \mathrm{g} / \mathrm{mL}$ (Figure 6a). 
The purified carbonaceous C-dot core CAPDA-p and CAEDA-p were studied by applying fluorescence lifetime imaging microscopy (FLIM). In aqueous solution, bi-exponential fluorescent decays of the carbonaceous cores CAPDA-p and CAEDA-p were observed after excitation at $810 \mathrm{~nm}$ and average lifetimes of $10.1 \mathrm{~ns}$ and $9.7 \mathrm{~ns}$ were determined, respectively (Figure 6b). Next, we recorded the FLIM signals inside living HeLa cell after $810 \mathrm{~nm}$ excitation. The average lifetimes of both C-dots decreased significantly inside cells compared to the bulk solvent, which was expected as many new non-radiative pathways could exist in this complex biological environment. A similar biexponential decay with an average lifetime of $1.2 \mathrm{~ns}$ and $3 \mathrm{~ns}$ was observed in FLIM for C-dot CAPDA-p and CAEDA-p, respectively (Figure 6c, 6d).

(a)

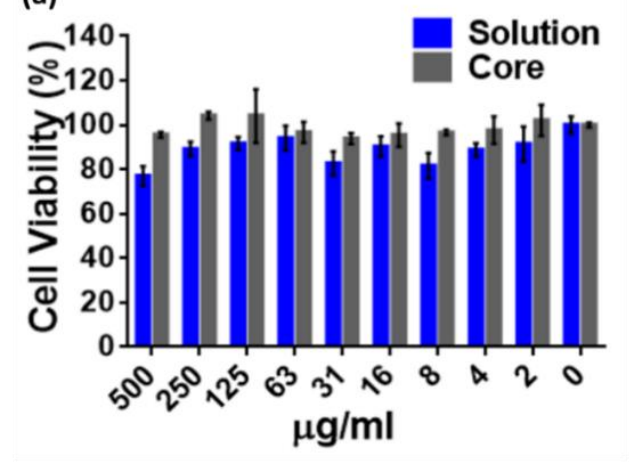

(b)
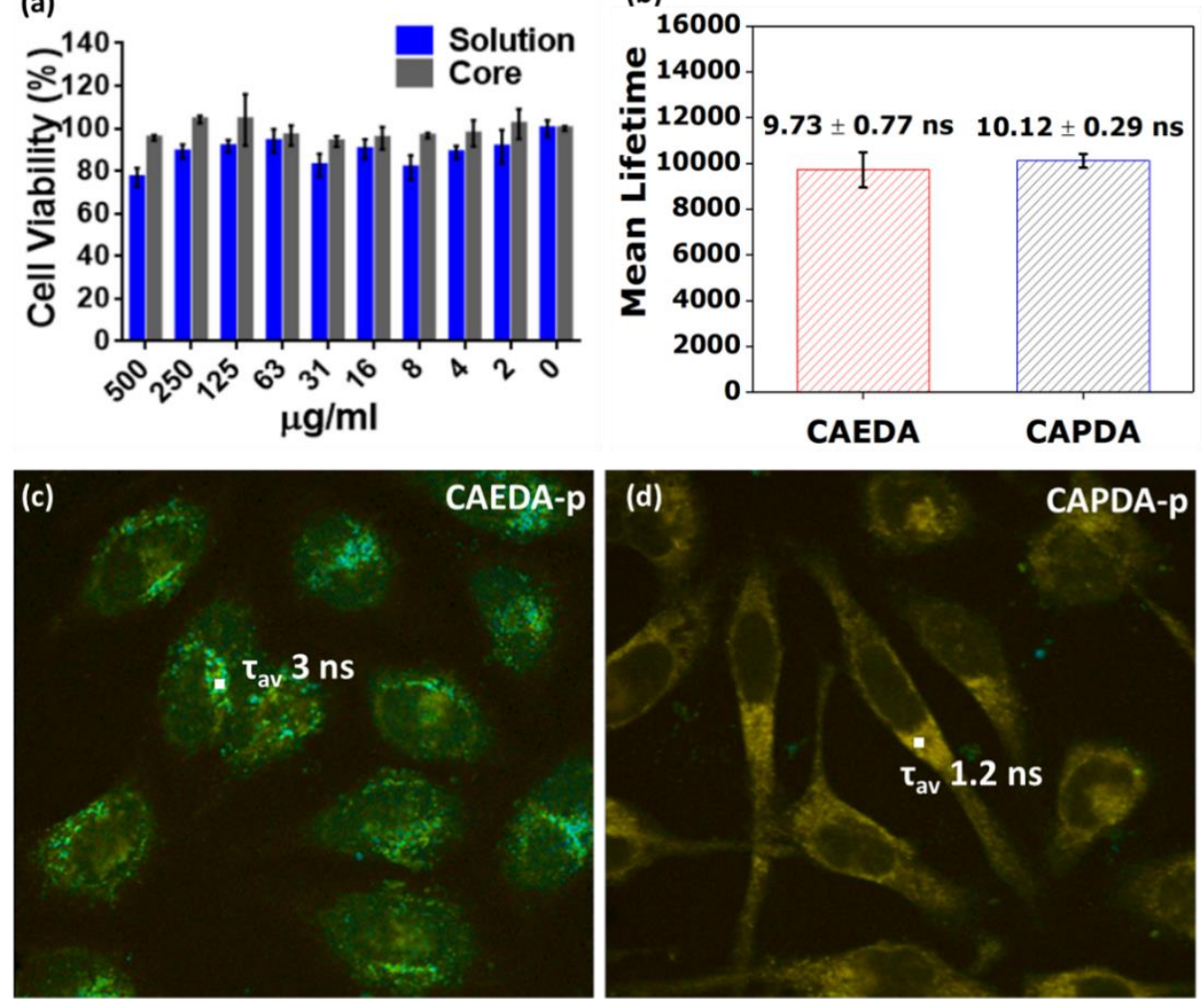

5000 ps

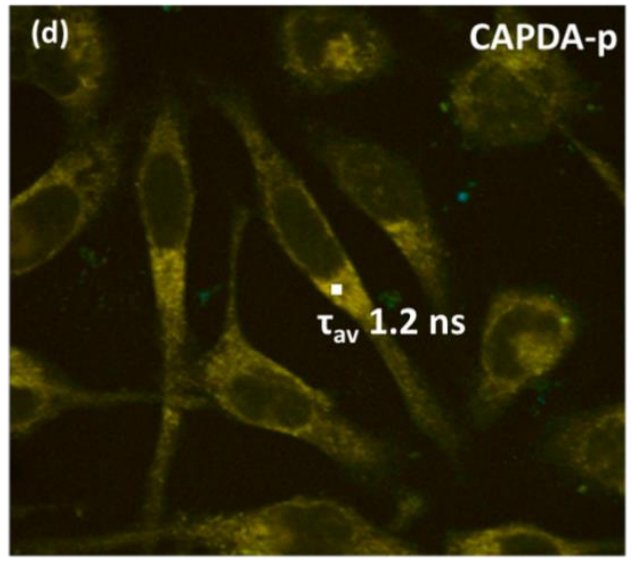

$0 \mathrm{ps}$ 
Figure 6. (a) Cell viability assays of CAPDA carbon nanodot solution and the associated purified carbonaceous core CAPDA-p over a concentration range of $0-500 \mu \mathrm{g} / \mathrm{mL}$ under dark conditions. The purified C-dot CAPDA-p and the fluorophores were well tolerated by Hela cells. (b) Fluorescence lifetime of C-dots CAEDA and CAPDA in solution. (c,d) Fluorescence lifetime images of C-dots inside HeLa cells. A relatively higher fluorescence lifetime of carbonaceous core CAEDA- $p$ as compared to CAPDA- $p$ was observed.

\section{Conclusions}

We have prepared three different $\mathrm{C}$-dots based on aliphatic and aromatic molecular precursors and analysed their structural and optical characteristics. During microwave synthesis, organic fluorophores associated with C-dot structures were formed in the C-dots CAPDA and CAEDA. We have separated the fluorophores from these C-dots and elucidated their molecular structure by NMR and mass spectrometry. Differences in the molecular structures of the formed fluorophore are responsible for the unique two-photon emission properties of the C-dots. The emergence of two-photon emission was observed and correlated to the hybridization state of the carbon atoms within the C-dot as well as the fluorophores associated to the C-dots. Higher two-photon absorption cross section was observed for CAPDA C-dots, which contained higher amounts of $\pi$-electrons in the fluorophores and carbonaceous core morphology. The fluorophores were bound to the Cdots via non-covalent as well as covalent interaction and revealed higher photostability in the presence of the C-dots. The C-dots CAPDA and CAEDA were non-toxic in a cell model and fluorescence lifetime imaging was performed inside cells.

We believe that an improved understanding of the impact of the precursor molecules on the molecular structure of the C-dot core and the formed organic fluorophores would enable to rationally design $\mathrm{C}$-dots with improved optical features, which would be of great relevance for their applications. We envision new avenues to design and tune tailor-made C-dots with 
improved quantum yield, enhanced two-photon emission and excellent photostability for bioimaging, therapeutic and other relevant biomedical applications.

\section{Conflicts of interest}

There are no conflicts to declare.

\section{Acknowledgement}

We acknowledge Prof. Dr. Thomas Diemant (University of Ulm) for XPS measurements, Dr. Goenuel Kizilsavas for support in NMR measurements and data analysis, Dr. Sviatlana Kalinina and Dr. Angelika Rueck for help in fluorescence lifetime measurements, Prof. Dr. Paul Walther (Central Facility for Electron Microscopy, Ulm University) for support in TEM measurements, Dr. Rongji Liu for cyclic voltammetry measurements, Carola Hoffmann-Richter (Ulm University) for AFM measurements, Dr. Todd Zapata (Max Planck Institute for Polymer Research) for Raman measurements, Markus Lamla (Department of Organic Chemistry III, Ulm University) for support in ESI-MS measurements, Prof. Dr. Alexander Kühne (Department of Organic Chemistry III, Ulm University) for support in FL 6500 Pulse Fluorescence Spectrophotometer measurements, Prof. Dr. Ulrich Ziener (Department of Organic Chemistry III, Ulm University) for support in Fluoromax-3 Spectrofluorimeter measurements, Dr. Sylvia Schmid (Ulm University) for help in circular dichroism measurements and Dr. Stephan Fischer (Ulm University) for cell experiments. The project was financial supported by the Deutsche Forschungsgemeinschaft under project number 316249678 - SFB 1279 (C04, Z01) and the Baden-Württemberg 
Stiftung (project: "intelligent optical biosensors") via the research program "Photonics, Microelectronics, Information technology: Intelligent Optical Sensors”.

\section{References}

1 Q. Li, T. Y. Ohulchanskyy, R. Liu, K. Koynov, D. Wu, A. Best, R. Kumar, A. Bonoiu and P. N. Prasad, J. Phys. Chem. C, 2010, 114, 12062-12068.

2 H. Peng and J. Travas-Sejdic, Chem. Mater., 2009, 21, 5563-5565.

3 M. Shim, N. W. Shi Kam, R. J. Chen, Y. Li and H. Dai, Nano Lett., 2002, 2, 285-288.

4 C. Fowley, N. Nomikou, A. P. McHale, B. McCaughan and J. F. Callan, Chem. Commun., 2013, 49, 89348936.

5 J. Wang, Z. Zhang, S. Zha, Y. Zhu, P. Wu, B. Ehrenberg and J.-Y. Chen, Biomaterials, 2014, 35, 93729381.

6 S. Zhu, Q. Meng, L. Wang, J. Zhang, Y. Song, H. Jin, K. Zhang, H. Sun, H. Wang and B. Yang, Angew. Chem. Int. Ed., 2013, 52, 3953-3957.

7 L. Cao, X. Wang, M. J. Meziani, F. Lu, H. Wang, P. G. Luo, Y. Lin, B. A. Harruff, L. M. Veca, D. Murray, S.Y. Xie and Y.-P. Sun, J. Am. Chem. Soc., 2007, 129, 11318-11319.

8 H. Yu, Y. Zhao, C. Zhou, L. Shang, Y. Peng, Y. Cao, L.-Z. Wu, C.-H. Tung and T. Zhang, J. Mater. Chem. A, 2014, 2, 3344-3351.

9 J. Tang, B. Kong, H. Wu, M. Xu, Y. Wang, Y. Wang, D. Zhao and G. Zheng, Adv. Mater., 2013, 25, 65696574.

10 Z. Ma, Y.-L. Zhang, L. Wang, H. Ming, H. Li, X. Zhang, F. Wang, Y. Liu, Z. Kang and S.-T. Lee, ACS Appl. Mater. Interfaces, 2013, 5, 5080-5084.

11 S.-L. Hu, K.-Y. Niu, J. Sun, J. Yang, N.-Q. Zhao and X.-W. Du, J. Mater. Chem., 2009, 19, 484-488.

12 Z.-A. Qiao, Y. Wang, Y. Gao, H. Li, T. Dai, Y. Liu and Q. Huo, Chem. Commun., 2009, 46, 8812-8814.

13 Q.-L. Zhao, Z.-L. Zhang, B.-H. Huang, J. Peng, M. Zhang and D.-W. Pang, Chem. Commun., 2008, 51165118.

14 Q. Wang, X. Liu, L. Zhang and Y. Lv, Analyst, 2012, 137, 5392-5397.

15 H. Li, X. He, Y. Liu, H. Huang, S. Lian, S.-T. Lee and Z. Kang, Carbon, 2011, 49, 605-609.

16 Y. Zhou, A. Desserre, S. K. Sharma, S. Li, M. H. Marksberry, C. C. Chusuei, P. L. Blackwelder and R. M. Leblanc, ChemPhysChem, 2017, 18, 890-897.

17 S. Cailotto, E. Amadio, M. Facchin, M. Selva, E. Pontoglio, F. Rizzolio, P. Riello, G. Toffoli, A. Benedetti and A. Perosa, ACS Med. Chem. Lett., 2018, 9, 832-837.

18 D. Zhao, X. Liu, Z. Zhang, R. Zhang, L. Liao, X. Xiao and H. Cheng, Nanomaterials, 2019, 9, 1556.

19 F. Wang, S. Wang, Z. Sun and H. Zhu, Fullerenes, Nanotubes, Carbon Nanostruct., 2015, 23, 769-776.

20 D. Qu, M. Zheng, L. Zhang, H. Zhao, Z. Xie, X. Jing, R. E. Haddad, H. Fan and Z. Sun, Sci. Rep., 2014, 4, 5294.

21 Y. Song, S. Zhu, S. Zhang, Y. Fu, L. Wang, X. Zhao and B. Yang, J. Mater. Chem. C, 2015, 3, 5976-5984.

22 M. J. Krysmann, A. Kelarakis, P. Dallas and E. P. Giannelis, J. Am. Chem. Soc., 2012, 134, 747-750.

23 A. Sharma, T. Gadly, A. Gupta, A. Ballal, S. K. Ghosh and M. Kumbhakar, J. Phys. Chem. Lett., 2016, 7, 3695-3702.

24 M. Shamsipur, A. Barati, A. A. Taherpour and M. Jamshidi, J. Phys. Chem. Lett., 2018, 9, 4189-4198.

25 Y. Deng, X. Chen, F. Wang, X. Zhang, D. Zhao and D. Shen, Nanoscale, 2014, 6, 10388-10393. 
26 G. Eda, Y.-Y. Lin, C. Mattevi, H. Yamaguchi, H.-A. Chen, I.-S. Chen, C.-W. Chen and M. Chhowalla, Adv. Mater., 2010, 22, 505-509.

27 S. Chen, N. Ullah and R. Zhang, J. Phys. Chem. Lett., 2018, 9, 4857-4864.

28 W. Kwon and S.-W. Rhee, Chem. Commun., 2012, 48, 5256-5258.

29 W. Kwon, G. Lee, S. Do, T. Joo and S.-W. Rhee, Small, 2014, 10, 506-513.

30 H. Li, X. He, Z. Kang, H. Huang, Y. Liu, J. Liu, S. Lian, C. H. A. Tsang, X. Yang and S.-T. Lee, Angew. Chem. Int. Ed., 2010, 49, 4430-4434.

31 L. Tang, R. Ji, X. Li, K. S. Teng and S. P. Lau, Part. Part. Syst. Charact., 2013, 30, 523-531.

32 X. Wang, L. Cao, S.-T. Yang, F. Lu, M. J. Meziani, L. Tian, K. W. Sun, M. A. Bloodgood and Y.-P. Sun, Angew. Chem. Int. Ed., 2010, 49, 5310-5314.

33 X. Xu, R. Ray, Y. Gu, H. J. Ploehn, L. Gearheart, K. Raker and W. A. Scrivens, J. Am. Chem. Soc., 2004, 126, 12736-12737.

34 Y.-P. Sun, B. Zhou, Y. Lin, W. Wang, K. A. S. Fernando, P. Pathak, M. J. Meziani, B. A. Harruff, X. Wang, H. Wang, P. G. Luo, H. Yang, M. E. Kose, B. Chen, L. M. Veca and S.-Y. Xie, J. Am. Chem. Soc., 2006, 128, 7756-7757.

35 L. Bao, Z.-L. Zhang, Z.-Q. Tian, L. Zhang, C. Liu, Y. Lin, B. Qi and D.-W. Pang, Adv. Mater., 2011, 23, 58015806.

36 H. Zheng, Q. Wang, Y. Long, H. Zhang, X. Huang and R. Zhu, Chem. Commun., 2011, 47, 10650-10652.

37 H. Liu, T. Ye and C. Mao, Angew. Chem. Int. Ed., 2007, 46, 6473-6475.

38 X. Wen, P. Yu, Y.-R. Toh, X. Hao and J. Tang, Adv. Opt. Mater., 2013, 1, 173-178.

39 P. Yu, X. Wen, Y.-R. Toh and J. Tang, J. Phys. Chem. C, 2012, 116, 25552-25557.

40 L. Wang, S.-J. Zhu, H.-Y. Wang, S.-N. Qu, Y.-L. Zhang, J.-H. Zhang, Q.-D. Chen, H.-L. Xu, W. Han, B. Yang and H.-B. Sun, ACS Nano, 2014, 8, 2541-2547.

41 S. K. Das, Y. Liu, S. Yeom, D. Y. Kim and C. I. Richards, Nano Lett., 2014, 14, 620-625.

42 Y. Song, S. Zhu, S. Xiang, X. Zhao, J. Zhang, H. Zhang, Y. Fu and B. Yang, Nanoscale, 2014, 6, 4676.

43 Y. I. Park, K. T. Lee, Y. D. Suh and T. Hyeon, Chem. Soc. Rev., 2015, 44, 1302-1317.

44 M. Rubart, Circ. Res., 2004, 95, 1154-1166.

45 L. Cao, X. Wang, M. J. Meziani, F. Lu, H. Wang, P. G. Luo, Y. Lin, B. A. Harruff, L. M. Veca, D. Murray, S.Y. Xie and Y.-P. Sun, J. Am. Chem. Soc., 2007, 129, 11318-11319.

46 X. Jia, J. Li and E. Wang, Nanoscale, 2012, 4, 5572-5575.

47 J. Zong, Y. Zhu, X. Yang, J. Shen and C. Li, Chem. Commun., 2011, 47, 764-766.

48 Y. Wang and A. Hu, J. Mater. Chem. C, 2014, 2, 6921-6939.

49 J. Shen, Y. Zhu, C. Chen, X. Yang and C. Li, Chem. Commun., 2011, 47, 2580-2582.

50 X. Wen, P. Yu, Y.-R. Toh, X. Ma and J. Tang, Chem. Commun., 2014, 50, 4703-4706.

51 V. Strauss, J. T. Margraf, C. Dolle, B. Butz, T. J. Nacken, J. Walter, W. Bauer, W. Peukert, E. Spiecker, T. Clark and D. M. Guldi, J. Am. Chem. Soc., 2014, 136, 17308-17316.

52 X. Wang, X.-C. Xu, M. Yang, P. Jiang, J. Zhao, F.-L. Jiang and Y. Liu, New J. Chem., 2019, 43, 8950-8957. 53 S. Zhu, Q. Meng, L. Wang, J. Zhang, Y. Song, H. Jin, K. Zhang, H. Sun, H. Wang and B. Yang, Angew. Chem. Int. Ed., 2013, 52, 3953-3957.

54 B. Geng, D. Yang, D. Pan, L. Wang, F. Zheng, W. Shen, C. Zhang and X. Li, Carbon, 2018, 134, 153-162. 55 B. Shi, Y. Su, L. Zhang, M. Huang, R. Liu and S. Zhao, ACS Appl. Mater. Interfaces, 2016, 8, 10717-10725. 56 R.-J. Fan, Q. Sun, L. Zhang, Y. Zhang and A.-H. Lu, Carbon, 2014, 71, 87-93.

57 K. Jiang, S. Sun, L. Zhang, Y. Lu, A. Wu, C. Cai and H. Lin, Angew. Chem. Int. Ed., 2015, 54, 5360-5363. 58 X. Ren, J. Liu, X. Meng, J. Wei, T. Liu and F. Tang, Chem. - Asian J., 2014, 9, 1054-1059.

59 S. R. Ankireddy and J. Kim, Sens. Actuators, B Chem., 2018, 255, 3425-3433.

60 P. Dash, T. Dash, T. K. Rout, A. K. Sahu, S. K. Biswal and B. K. Mishra, RSC Adv., 2016, 6, 12657-12668.

61 P. Shen and Y. Xia, Anal. Chem., 2014, 86, 5323-5329.

62 A. Sciortino, A. Cannizzo and F. Messina, C, 2018, 4, 67. 
63 J. Titantah and D. Lamoen, Phys. Rev. B, 2004, 70, 075115.

64 M. Diociaiuti, S. Casciardi and R. Sisto, Micron, 2016, 90, 97-107.

65 A.-L. Hamon, J. Verbeeck, D. Schryvers, J. Benedikt and R. M. C. M. v. d. Sanden, J. Mater. Chem., 2004, 14, 2030.

66 S. E. Ashbrook and M. J. Duer, Concepts Magn. Reson. Part A, 2006, 28A, 183-248.

67 Z. Qian, J. Ma, X. Shan, H. Feng, L. Shao and J. Chen, Chem. - Eur. J., 2014, 20, 2254-2263.

68 M. J. Frisch, G. W. Trucks, H. B. Schlegel, G. E. Scuseria, M. A. Robb, J. R. Cheeseman, G. Scalmani, V. Barone, G. A. Petersson, H. Nakatsuji, X. Li, M. Caricato, A. V. Marenich, J. Bloino, B. G. Janesko, R. Gomperts, B. Mennucci, H. P. Hratchian, J. V. Ortiz, A. F. Izmaylov, J. L. Sonnenberg, Williams, F. Ding, F. Lipparini, F. Egidi, J. Goings, B. Peng, A. Petrone, T. Henderson, D. Ranasinghe, V. G. Zakrzewski, J. Gao, N. Rega, G. Zheng, W. Liang, M. Hada, M. Ehara, K. Toyota, R. Fukuda, J. Hasegawa, M. Ishida, T. Nakajima, Y. Honda, O. Kitao, H. Nakai, T. Vreven, K. Throssell, J. A. Montgomery Jr., J. E. Peralta, F. Ogliaro, M. J. Bearpark, J. J. Heyd, E. N. Brothers, K. N. Kudin, V. N. Staroverov, T. A. Keith, R. Kobayashi, J. Normand, K. Raghavachari, A. P. Rendell, J. C. Burant, S. S. Iyengar, J. Tomasi, M. Cossi, J. M. Millam, M. Klene, C. Adamo, R. Cammi, J. W. Ochterski, R. L. Martin, K. Morokuma, O. Farkas, J. B. Foresman and D. J. Fox, Gaussian 09W 9.5 Revision D.01, Gaussian, Inc., Wallingford, CT, 2009.

69 G. Eda, Y.-Y. Lin, C. Mattevi, H. Yamaguchi, H.-A. Chen, I.-S. Chen, C.-W. Chen and M. Chhowalla, Adv. Mater., 2010, 22, 505-509.

70 J. Tang, B. Kong, H. Wu, M. Xu, Y. Wang, Y. Wang, D. Zhao and G. Zheng, Adv. Mater., 2013, 25, 65696574.

71 P. Gong, L. Sun, F. Wang, X. Liu, Z. Yan, M. Wang, L. Zhang, Z. Tian, Z. Liu and J. You, Chem. Eng. J., 2019, 356, 994-1002.

72 M. Thakur, S. Pandey, A. Mewada, V. Patil, M. Khade, E. Goshi and M. Sharon, J. Drug Deliv., 2014, 2014, 1-9.

73 S. Li, D. Amat, Z. Peng, S. Vanni, S. Raskin, G. D. Angulo, A. M. Othman, R. M. Graham and R. M. Leblanc, Nanoscale, 2016, 8, 16662-16669.

74 M. Lan, S. Zhao, Z. Zhang, L. Yan, L. Guo, G. Niu, J. Zhang, J. Zhao, H. Zhang, P. Wang, G. Zhu, C.-S. Lee and W. Zhang, Nano Res., 2017, 10, 3113-3123. 